\title{
Los nuevos estudiantes en la carrera de Medicina. La visión de ocho generaciones: 2008 a 2015
}

\section{New students in medical school. The vision of eight generations: 2008 to 2015}

DOI: $10.46932 / \mathrm{sfjdv} 2 \mathrm{n} 3-042$

Received in: May 1st, 2021

Accepted in: Jun 30th, 2021

\section{Bernabé Ríos Nava}

Doctor en educación. Unidad Académica de Medicina. Universidad Autónoma de Nayarit. Avenida de la Cultura S/N. Col. Centro. Tepic, Nayarit. Cp 63000

E-mail: brios402017@gmail.com

\section{J. Ramón Olivo Estrada}

Doctor en educación. Unidad Académica de Economía. Universidad Autónoma de Nayarit. Avenida de la Cultura S/N. Col. Centro. Tepic, Nayarit. Cp 63000

E-mail: jrolivo@gmail.com.

\section{RESUMEN}

La Unidad Académica de Medicina (UAM) de la Universidad Autónoma de Nayarit (UAN) es la principal institución formadora de médicos en la entidad. Cada ciclo escolar, de acuerdo al número de aspirantes, se muestra como la primera opción y la más solicitada para los egresados de la educación media superior. El pasado ciclo 2015-2016 el número de aspirantes superó los 1,400. Se ha observado que los estudiantes de primer ingreso, desde hace ocho años, han mostrado, a lo largo de su vida familiar y social, diversos cambios socioeconómicos y familiares, que han impactado de manera importante el curriculum y la organización interna de la institución. A partir de esta realidad, se hace un análisis de estos y se los relaciona con aspectos de infraestructura, situación y condiciones laborales del personal y cuerpos académicos.

Palabras clave: estudiantes, estudiantes universitarios, estudios de perfil

\begin{abstract}
The Academic Unit of Medicine (UAM) of the Autonomous University of Nayarit (UAN) is the main medical training institution in the state. Each school year, according to the number of applicants, it is shown as the first and most requested option for high school graduates. Last 2015-2016 cycle, the number of applicants exceeded 1,400. It has been observed that first year students, since eight years ago, have shown, throughout their family and social life, several socioeconomic and family changes, which have significantly impacted the curriculum and the internal organization of the institution. Based on this reality, an analysis of these changes is made and they are related to aspects of infrastructure, situation and working conditions of the staff and academic bodies.
\end{abstract}

Key words: students, university students, profile studies. 


\section{INTRODUCCIÓN}

Inaugurada en la década de los setentas (1974) la entonces Escuela Superior de Medicina de la Universidad de Nayarit hoy Unidad Académica de Medicina (UAM) de la Universidad Autónoma de Nayarit (UAN) se ha constituido como la principal institución formadora de médicos cirujanos ${ }^{1}$, egresando a 3,300 médicos hasta el momento. En cada ciclo escolar es la primera opción para los egresados de educación media superior en el estado. Motivo por el cual es de las unidades académicas que recibe el mayor número de solicitudes de ingreso: 1,400 en promedio. Se ubica en el área de Ciencias de la Salud ${ }^{2}$ y por la población escolar que alberga, por ejemplo, ocupó el segundo lugar en el ciclo escolar (2013-2014) después del área de Ciencias Económico Administrativas. A la par de estos cambios institucionales percibimos que también las poblaciones escolares, particularmente las de primer ingreso a la institución han venido experimentando, de unos años a la fecha, diversas transformaciones que han tenido un impacto sustancial en su organización interna y en su curriculum.

En el año 2008 iniciamos las investigaciones sobre el perfil (características socioeconómicas y origen social; recursos, infraestructura, comunicación y equipos de apoyo para los estudios; orientación profesional y expectativas futuras; estudio en el nivel medio superior; ingreso y apreciación a la universidad) de los estudiantes de primer ingreso a la UAM con el propósito de conocer parte de estos cambios. Este acercamiento a ocho generaciones (2008 a 2015) nos muestra sus primeros trazos: menor presencia de estudiantes-trabajadores; una mayoría joven, soltera y citadina (la generalidad nació en la capital del estado); un predominio de mujeres; mayor conocimiento y destrezas en informática, comunicación vía internet, redes sociales; y de padres con mayores niveles de estudio. A la presente investigación la acompañan dos interrogantes: ¿Qué aspectos socioeconómicos y demográficos de la población escolar han mostrado cambios sustanciales?, ¿cuál será su impacto hacia la organización interna de la institución universitaria?

\section{METODOLOGÍA}

Se describen las dimensiones: características socioeconómicas y origen social; recursos, infraestructura, comunicación y equipos de apoyo para los estudios; orientación profesional y expectativas futuras, que han sido experimentados en ocho generaciones de estudiantes de primer ingreso a la UAM y se explica su impacto hacia los rubros: infaestructura, población docente y cuerpos académicos. La información sobre las generaciones se obtuvo de los estudios de perfil de estudiantes de primer ingreso:

\footnotetext{
${ }^{1}$ Actualmente la capital del estado cuenta con dos instituciones privadas: el Instituto Universitario de Ciencias Médicas y Humanísticas de Nayarit (INUMEDH) y la Universidad Cuauhtémoc.

${ }^{2}$ El área cuenta además con las carreras de Nutrición, Odontología, Enfermería, Cultura Física y Deporte, Qfb y profesional asociado en Terapia Física y Atención Geriátrica. (UAN, 2015)
} 
generaciones 2008 a 2015, que al respecto hemos venidos realizando durante este tiempo. Para el proceso de la información trabajamos los programas: IBM SPSS v. 17 y Microsoft Office Excel 2007.

\section{RESULTADOS}

A fines de la década de los noventa, la (UAN) — como muchas de las IES mexicanas - entra en un amplio proceso de reforma, producto de la interacción de actores internos-externos a las instituciones (López, 2003), que impactó, en todos sus órdenes, la vida institucional de la (UAM); la cual se vio marcada por un proceso de grandes cambios: curriculares, administrativos, cambio generacional de su personal docente y administrativo, de infraestructura - entre otros-. Esta transformación paulatina en la UAM se muestra en los siguientes hechos: a nivel de licenciatura cambió el Programa de Medicina General Integral A-36, por el de Competencias Profesionales Integradas; logró su acreditación y posterior re-acreditación ${ }^{3}$; se ubica en el lugar número 12 a nivel nacional ${ }^{4}$; cuenta con un total de 193 profesores (99 de base y 94 eventuales) de ellos el $34.1 \%$ tiene estudios de licenciatura; $30.1 \%$ especialidad; $5.2 \%$ subespecialidad; $22.3 \%$ maestría y $8.3 \%$ doctorado; 17 docentes cuentan con Perfil Promep; 2 profesores son candidatos al Sistema Nacional de Investigadores (SNI) de CONACYT y dos se ubican en el Nivel 1; 45 trabajadores son personal administrativo. En el renglón de la investigación cuenta con cuatro cuerpos académicos del área y uno más que combina personal docente de diversas unidades académicas, uno se encuentra en Consolidación y los demás en el nivel de en Formación de acuerdo a la clasificación de Promep; sobre la difusión de los trabajos de investigación, para el año 2013: 11(34\%) artículos aparecieron en revistas indexadas; seis (19\%) en revistas no arbitradas y 15 (47\%) en memorias por la participación en congresos.

Respecto de su infraestructura, aun cuando continúa sin ampliar el número de aulas (8), ha tenido algunas mejoras importantes: se acondicionó su auditorio; su sala de cómputo que está en vías de actualizar sus 30 equipos; sanitarios y pasillos; la totalidad de sus aulas se equiparon con nuevos equipos de aire acondicionado, pantallas, proyectores y equipos de cómputo; sus laboratorios para prácticas tuvieron mejoras físicas y de equipamiento y en su área de posgrado se remodelaron: aulas, oficinas y sanitarios. (UAN, 2014)

\footnotetext{
${ }^{3}$ El día 20 de mayo de 2008 la UAM recibe por parte del COMAEM la placa y documentación que avala la acreditación de su programa de licenciatura de Médico Cirujano, con una vigencia de cinco años (31 de enero de 2008 al 31 de enero de 2013 ). En septiembre de 2013, recibe el dictamen favorable a su re-acreditación para el periodo 2013-2018. (COMAEM; UAN, 2008; UAN, 2013). En el área también se encuentran acreditados los programas de Enfermería y Odontología.

${ }^{4}$ Ranking general de Instituciones de Educación Superior del El Universal Online. (UAN, 2015)
} 


\subsection{CARACTERÍSTICAS SOCIOECONÓMICAS Y ORIGEN SOCIAL.}

La población encuestada de las ocho generaciones fue de 1,036 estudiantes (ver gráfica 1). Durante este tiempo la matrícula ha mostrado un aumento en el número de escolares admitidos; de la generación 2008 a la 2015 creció en un 35\%. Esto se debe en parte a la presión social (sindicatos, senadores, diputados, federaciones de estudiantes) que recibe la institución — en cada nuevo ciclo escolar — para abrir un mayor número de lugares, a pesar de que no han crecido su infraestructura ni el número de espacios hospitalarios de enseñanza.

Gráfica 1

\section{Población escolar de primer ingreso según generación}

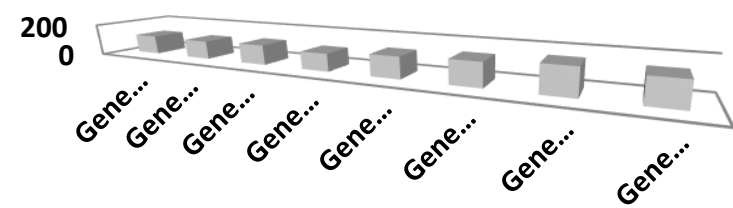

Fuente: Investigación directa

En la conformación de la matrícula las mujeres han venido distinguiéndose como el grupo predominante. Este proceso de "feminización" nuestro caso- empezó a dar sus primeros signos a mediados de la década de los ochenta del siglo pasado. En la actualidad el fenómeno, como ha ocurrido en otras instituciones, se ha consolidado. De esta manera, las mujeres representan —en número totales - el 52.54\% frente al $46.6 \%$ de los hombres. Aun cuando en las generaciones 2010 y 2012 el número de varones llegó a equiparse al grupo femenino. ${ }^{6}$

Por lo que toca al grupo etario, el mayor número de integrantes se ubica en el rango de 15 a 19 años $(83.17 \%)^{7}$; ello quiere decir, que mantuvieron de manera constante una trayectoria escolar en sus estudios de preparatoria. Sin embargo, se observa que el grupo de 20 a 24 años, aquellos estudiantes que por alguna circunstancia — problemas familiares, reprobación, cuestiones de salud, etcéterainterrumpieron sus estudios, constituyen el segundo grupo con el 15.46\%; llama la atención que este haya crecido de manera importante en las últimas generaciones y particularmente en la 2013. Otra

\footnotetext{
${ }^{5}$ Se expresa a la feminización como el fenómeno histórico social que nos explica la presencia, orígenes, trascendencia y visiones futuras de las mujeres en diversos espacios de la educación, la profesión, la docencia e investigación. (Pamo, 2007; Arrizabalaga y Valls, 2005; Flores, 2012)

${ }^{6}$ La presencia de la mujer en la educación superior mexicana ha mostrado un cambio sostenido, el periodo más significativo ha sido de 1969 al 2000, cuyo incremento pasó del 17\% al 50\%. En el Área de (CS), entre 1980 y fines de los noventa los hombres pasaron del $57 \%$ al $40 \%$. En contraparte las mujeres mostraron porcentajes de participación del 35\% al $61 \%$. (Bustos, 2003; Augusto, 2007)

${ }^{7}$ En el caso de la UAM-A el 35.5\% de los jóvenes de nuevo ingreso tenían entre 17 y 18 años y el 19.4\% 19 años. (UAM, 2012)
} 
particularidad de los estudiantes médicos la encontramos cuando nos referimos a la condición de ser estudiante y trabajador durante los estudios universitarios ${ }^{8}$. Encontramos que en las ocho generaciones el número de estos es muy reducido, escasamente supera el $10 \%$ de la población ${ }^{9}$.

Los padres de familia. La condición socioeconómica, cultural y educativa de los padres de familia, tendrán influencia decisiva en el trayecto educativo de los estudiantes de primer ingreso a la universidad. Pascarella y Terenzini (2005) afirman que el capital educativo familiar puede jugar un papel relevante en el medio universitario. Al interior del grupo de padres de familia (ver cuadro 1) encontramos tres grupos, y su distribución es la siguiente: el más importante lo representan quienes cursan o cursaron sus estudios de licenciatura; durante todo este tiempo el grupo muestra un crecimiento estable, salvo en las generaciones 2010, 2012 y 2015. El siguiente grupo lo integran quienes cursan o cursaron estudios a nivel básico (primaria, secundaria y bachillerato); llama la atención que durante estos años el grupo ha venido descendiendo al pasar del $30 \%$ al 22\%. El siguiente, lo forman quienes cursan o cursaron estudios a nivel posgrado; se advierte un crecimiento constante que alcanza el $60 \%{ }^{10}$.

Cuadro 1

\begin{tabular}{|c|c|c|c|c|c|c|c|c|c|c|c|c|c|c|c|c|}
\hline $\begin{array}{l}\text { Nivel de } \\
\text { escolaridad }\end{array}$ & $\begin{array}{c}\text { Genera } \\
\text { ción } \\
2008\end{array}$ & $\%$ & $\begin{array}{l}\text { Genera } \\
\text { ción } \\
2009\end{array}$ & $\%$ & $\begin{array}{c}\text { Genera } \\
\text { ción } \\
2010 \\
\end{array}$ & $\%$ & $\begin{array}{l}\text { Genera } \\
\text { ción } \\
2011\end{array}$ & $\%$ & $\begin{array}{c}\text { Genera } \\
\text { ción } \\
2012 \\
\end{array}$ & $\%$ & $\begin{array}{l}\text { Genera } \\
\text { ción } \\
2013\end{array}$ & $\%$ & $\begin{array}{l}\text { Genera } \\
\text { ción } \\
2014\end{array}$ & $\%$ & $\begin{array}{l}\text { Genera } \\
\text { ción } \\
2015\end{array}$ & $\%$ \\
\hline NINGUNA & 0 & 3 & 0 & 3 & 0 & 3 & 0 & 2 & 2 & 3 & 3.2 & 2 & 1 & 2 & 0 & 2 \\
\hline $\begin{array}{l}\text { PRIMARIA } \\
\text { PARCIAL }\end{array}$ & 3 & $\mathbf{0}$ & 4 & 2 & 4 & $\mathbf{0}$ & 5 & 8 & 2 & $\mathbf{0}$ & 2 & 5 & 8 & 2 & 5 & 8 \\
\hline $\begin{array}{l}\text { PRIMARIA } \\
\text { COMPLET } \\
\text { A }\end{array}$ & 10 & & 8 & & 6 & & 8 & & 15 & & 4 & & 6 & & 6 & \\
\hline $\begin{array}{l}\text { SECUNDA } \\
\text { RIA } \\
\text { PARCIAL }\end{array}$ & 6 & & 3 & & 7 & & 1 & & 4 & & 9 & & 2 & & 5 & \\
\hline $\begin{array}{l}\text { SECUNDA } \\
\text { RIA } \\
\text { COMPLET } \\
\text { A }\end{array}$ & 23 & & 17 & & 4 & & 13 & & 20 & & 17 & & 17 & & 23 & \\
\hline $\begin{array}{l}\text { BACHILLE } \\
\text { RATO } \\
\text { PARCIAL } \\
\end{array}$ & 10 & & 12 & & 14 & & 11 & & 7 & & 15 & & 13 & & 13 & \\
\hline $\begin{array}{l}\text { BACHILLE } \\
\text { RATO } \\
\text { COMPLET } \\
\mathrm{O} \\
\end{array}$ & 18 & & 30 & & 34 & & 22 & & 24 & & 18 & & 24 & & 30 & \\
\hline TÉCNICO & 16 & 1 & 18 & 9 & 17 & 1 & 25 & 1 & 33 & 1 & 27 & 1 & 30 & 1 & 18 & 1 \\
\hline NORMAL & 11 & 1 & 3 & & 8 & 1 & 0 & 2 & 8 & 6 & 1 & 0 & 7 & 2 & 9 & $\mathbf{0}$ \\
\hline
\end{tabular}

${ }^{8}$ Datos de la Encuesta Nacional de la Juventud 2010 muestran que en el grupo de 14 a 29 años, se dedicaban solo a estudiar el $32.7 \%$.

${ }^{9}$ En el caso de los estudiantes de la UAM-A se reportó que el $28 \%$ estudiaban y trabajaban. (UAM, 2012)

${ }^{10}$ En el caso de los estudiantes de la UAM-A los estudiantes "pioneros" representaron el 50\% y el $48 \%$ en aquellos jóvenes "herederos" o de segunda generación. (UAM, 2012) 


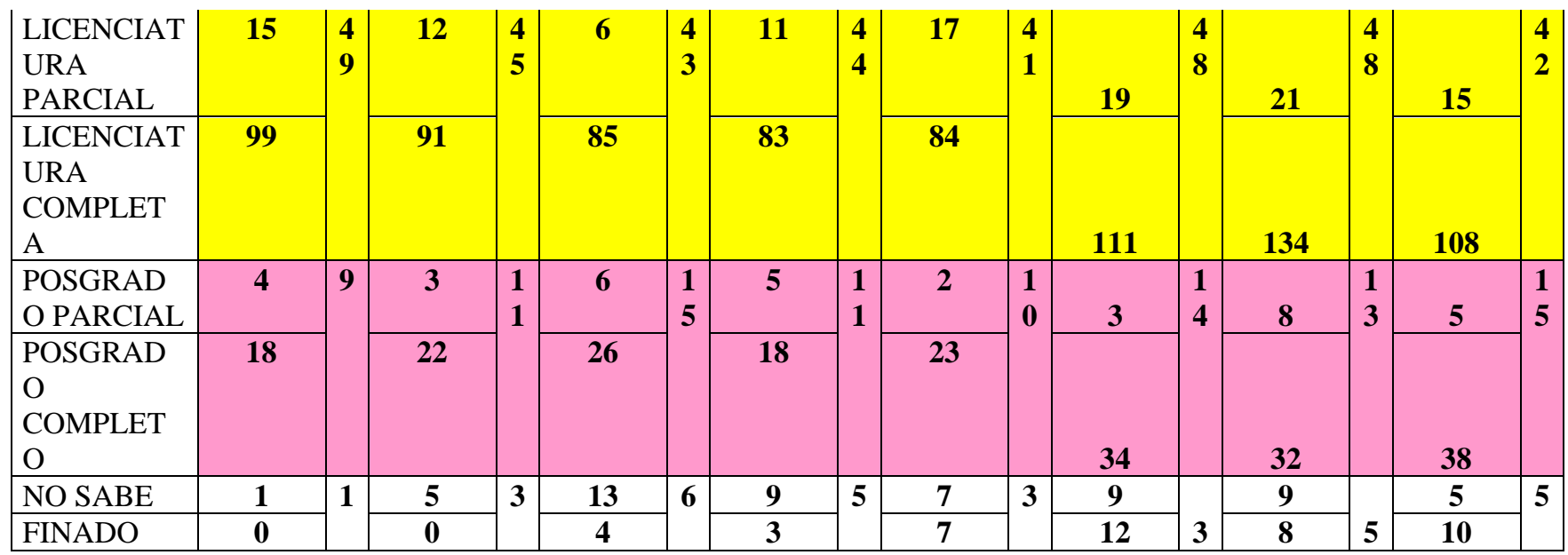

Fuente: Investigación directa

\subsection{RECURSOS, INFRAESTRUCTURA, COMUNICACIÓN Y EQUIPO DE APOYO PARA LOS}

\section{ESTUDIOS}

Para un óptimo desempeño dentro de la carrera universitaria, los recursos, infraestructura y equipos de apoyo constituyen un elemento sustancial. La posesión reflejará la situación socioeconómica de cada uno de los estudiantes y estos recursos jugarán un papel importante en la diferenciación estudiantil. Respecto de la posesión de computadora ${ }^{112}$ (ver gráfica 2) se advierte que en cada una de las generaciones este producto ha llegado a formar parte de las labores escolares ${ }^{1314}$. Así por ejemplo, para la generación 2008 representó el 96.6\%; para la generación 2009, 95.6\%; para la generación 2010, 98.4\%; en la generación 2011, 97.2\%; para la generación 2012, 97.7\%, para la generación 2013, 97.9\% para la generación 2014, 89\% y para la generación 2015, 80\%. La población escolar de la carrera de Medicina reporta uno de los porcentajes más altos dentro de la UAN.

Gráfica 2

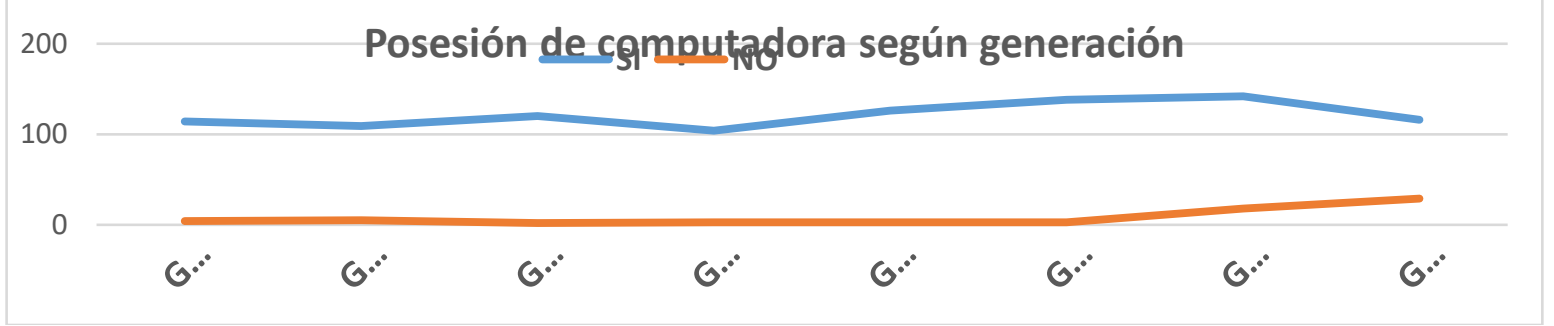

Fuente: Investigación directa

\footnotetext{
${ }^{11}$ La media de los países miembros de la OCDE pasó de $72 \%$ a 95\%. Sin embargo, nuestro país ocupa el lugar 57 de 65 , al pasar del 20\% en el año 2000 al 50\% a finales del 2010; encontrándose por arriba de Albania, Colombia, Panamá, Túnez, Perú, Azerbaiyán, Kazajistán e Indonesia. (Poy, 2012)

${ }^{12}$ La generación 2012 de la UAM-A reportó contar con ella en un 87\%. (UAM, 2012)

${ }^{13}$ En el estudio nacional, los estudiantes de universidades públicas, reportaban sí tenerla un 43.5\%. (De Garay, 2001). En el caso de los estudiantes de las Universidades Tecnológicas, la región Noroeste reportaba un 62.8\% y la región Centro-sur $28.7 \%$. (De Garay, 2006)

${ }^{14}$ La frecuencia de uso de la computadora fue reportado por los jóvenes de la siguiente manera: todos los días, 26.9\%; varias veces a la semana, $25.7 \%$ y una vez a la semana $11.6 \%$. (IMJUVE-IIJ, UNAM,2012)
} 
Actualmente el acceso a internet ${ }^{1516}$ desde casa se considera como uno de los recursos educativos indispensables que marcan diferencias cualitativas y cuantitativas fundamentales ${ }^{17}$. (OCDE, 2009) En cada una de las generaciones encontramos a un número creciente de estudiantes que cuentan ya con este apoyo. Así, para la generación 2008 representó el 79.7\% de la población; para la generación 2009, 80\%; para la generación 2010, 91\%; para la generación 2011,88.8\%, para la generación 2012, 87.6\% ${ }^{18}$, para la generación $2013,86.5 \%{ }^{1920}$, para la generación $2014,91 \%$ y para la generación 2015, 88\%.

\subsection{ORIENTACIÓN PROFESIONAL Y EXPECTATIVAS LABORALES FUTURAS}

Los primeros meses de estancia en la universidad serán importantes y definitivos al ayudar a los estudiantes de primer ingreso en su definición y reafirmación hacia la disciplina científica. En el caso de los estudiantes de la carrera de Medicina la decisión y el gusto por estudiarla ha ocurrido incluso antes de concluir sus estudios de preparatoria. Encontramos que desde la generación 2008 un alto porcentaje de estudiantes que se encuentran inscritos en la carrera universitaria que llena sus expectativas personales y profesionales, es decir, les gusta. Los resultados son los siguientes: 95.5\% para la generación 2008; 92.2\% para la generación 2009; para la generación 2010, 92\%; 95.52\%, para la generación 2011; 92\% de la generación 2012; 96.4\% para la generación 2013; 90\% para la generación 2014 y 97\% para la generación 2015.

\section{CONCLUSIONES}

A lo largo de los años ha cambiado la organización interna de la UAM: han aparecido y desaparecido departamentos, coordinaciones, programas, grupos de trabajo, proyectos. Su personal docente, administrativo y directivo ya no es el mismo, poco a poco empieza a mostrarse el cambio generacional. El clima organizacional empieza a tomar otros tintes. Las metas y propósitos institucionales han tenido también grandes cambios: la certificación de los procesos administrativos, la solvencia y respuesta a las recomendaciones del organismo acreditador COMAEM (Consejo Mexicano para la Acreditación de la Educación Médica A.C.). La población escolar ha marcado sus propias dinámicas

\footnotetext{
${ }^{15}$ Datos del INEGI muestran que el $76 \%$ de los cibernautas mexicanos tienen menos de 35 años, el $24 \%$ tienen una escolaridad de licenciatura y $2 \%$ posgrado; $26 \%$ de los hogares del país cuentan con conexión a internet. (INEGI)

${ }^{16}$ Considerando a los jóvenes entre 12 a 29 años por entidad federativa que tienen acceso a internet desde su domicilio, los de baja california ocupan el primer lugar con 48.8\%, Aguascalientes 36.4\%, Nayarit 26.5\%, Guanajuato 16.2\% y Chiapas 8.2\%. (ENJ, 2010)

${ }^{17}$ La media de los países miembros de la OCDE en conectividad a internet pasó del $45 \%$ al 89\%. (OCDE, 2009)

${ }^{18}$ En el estudio nacional, los estudiantes de universidades públicas reportaban contar con el servicio, 32.1\% (De Garay, 2001) Para los estudiantes de las Universidades Tecnológicas, el panorama es más crítico, la región Noroeste, Noreste y Centro-sur, para el año 2003, reportaban las siguientes cifras: $31.5 \%, 22.3 \%$ y $11.6 \%$ (De Garay, 2006)

${ }^{19}$ Datos nacionales muestran que los jóvenes entre 12 y 29 años, el $69.5 \%$ saben usar internet y $28.5 \%$ tienen acceso a internet desde su domicilio. (ENJ, 2010)

${ }^{20}$ En el caso de los estudiantes de la UAM-A el 76\% cuenta con el servicio de conectividad a internet. (UAM, 2012)
} 
durante los pasados ocho años. Se muestra una población con rasgos similares al de otras instituciones de nivel superior: su juventud, soltería y una mayoría citadina; la menor de hijos de padres de las etnias de la región. Las mujeres se han consolidado como grupo predominante, lo que corrobora los cambios ocurridos en la composición de la matrícula en las instituciones de educación superior (IES) mexicanas. Quienes combinan estudio y trabajo son pocos.

En el caso de los padres de familia el grupo mayoritario culminó estudios de licenciatura; así como de aquellos que están en proceso o han logrado concluir sus estudios de posgrado. Los altos porcentajes de posesión de recursos informáticos y de comunicación (computadoras personales/escritorio, tabletas, iPads y la conectividad a internet) nos muestran una realidad de alta exigencia para la institución; que se ha traducido en grandes inversiones para la remodelación de infraestructura, equipamiento y mantenimiento (aulas, auditorio). Los de instituciones particulares empiezan a ser mayoría en la matrícula, como son los casos de las generaciones 2010, 2012, 2014 y 2015. Los retos hacia la institución son complejos y apuntan a diversos frentes: el fundamental tiene relación con su planta docente y el cambio generacional que está experimentando.

Debe fortalecerse al profesor de tiempo completo (PTC), en diversas dimensiones: clima laboral, condición y situaciones laborales, desarrollo y superación académica; de no ser así se corren algunos riesgos: dejar de apoyar a los estudiantes en actividades como la tutoría o asesoría o fortalecer al trabajo de investigación de los cuerpos académicos, desestimular nuevos proyectos de desarrollo, etcétera. Pugnar por la clasificación y el reconocimiento de la categoría de profesor-investigador (a nivel institucional y sindical) y dotar de recursos y apoyos - lo que hasta el momento no ha sucedido - a los diversos cuerpos académicos para hacer más atractiva la actividad de investigación. 


\section{BIBLIOGRAFÍA CONSULTADA}

Augusto, Bolívar Espinoza y Oscar Cuéllar Saavedra, (2007). Participación y desempeño de las mujeres en la educación superior: Un enfoque desde las carreras de Sociología de la UAM 1974-2005. Revista de la Educación Superior. Disponible en http://publicaciones.anuies.mx/acervo/revsup/pdf/R ES_143.pdf. Consultado 18 julio 2014

Arrizabalaga, Pilar y Carme Valls-Llobet, (2005). Mujeres médicas: de la incorporación a la discriminación. Disponible en http://www.unc.edu.ar/exten sion-unc/vinculacion/instituciones-socialesy-salud/salud-derechos-humanos-y-genero-en-la-ensenanza-de-grado/mujeres-medicas.pdf.

Bustos, Romero Olga, (2003). Mujeres y educación superior en México. Recomposición de la matrícula universitaria a favor de las mujeres. Repercusiones educativas, económicas y sociales. Disponible $e n$ www.anuie s.mx/e_proyectos/pdf/generos_educ.pdf

Consejo Mexicano para la Acreditación de la Educación Médica. Acreditación de Estados. Disponible en http://comaem.org/Estado.php\#. Consultado 22 agosto 2014

De Garay, Sánchez Adrián, (2001). Los actores desconocidos. Una aproximación al conocimiento de los estudiantes. Colección Biblioteca de la Educación Superior. ANUIES. México. D.F.

----- (2006), Las Trayectorias Educativas en las Universidades Tecnológicas. Un acercamiento al modelo educativo desde las prácticas escolares de los jóvenes universitarios. SEP. SES. Coordinación General de Universidades Tecnológicas. Universidad Tecnológica de la Sierra Hidalguense. Bogotá, Colombia.

Encuesta Nacional de la Juventud 2010. Resultados Generales. Disponible en http://www.imjuventud.gob.mx/imgs/uploads/Encuesta_Nacional_de_Juventud_2010_-

_Resultados_Generales_18nov11.pdf. Consultado 5 agosto de 2014

Flores, Domínguez Carmina (2012). Feminización en Medicina: liderazgo y academia. Educ. Méx. Vol. 15 No. 4.Barcelona, dic. 2012. Disponible en http ://scielo.isciii.es/scielo.php?pid=S1575$18132012000400003 \&$ script=sciartt ext. Consultado 25 julio de 2014

IMJuve-IIJ, UNAM, (2012). Encuesta nacional de Valores en Juventud 2012. Informe gráfico. Disponible en http://www.juridicas.unam.mx/invest/areas/opi nion/envaj/pdf/resumen.pdf. Consultado 27 julio 2014

INEGI. Estadísticas a propósito del Día Mundial de Internet. Disponible en http://www.inegi.org.mx/inegi/contenidos/espanol/prensa/Contenidos/estadisticas/2013/internet0.pdf.

Consultado 20 agosto de 2014

OCDE, (2009). Informe PISA 2009. Estudiantes en Internet. Tecnologías y rendimiento digitales. Vol. VI. Disponible en http://www.keepeek.com/Digital-Asset-Management/oecd/education/informe-pisa2009-estudiantes-en-intern et_9788468012001-es\#page2. Consultado 21 agosto de 2014 